\title{
OS USOS DA COMPETÊNCIA LINGUÍSTICA ENTRE IMIGRANTES ALEMÃES DURANTE O ESTADO NOVO EM CURITIBA: UMA ANÁLISE MIGRATÓRIA À LUZ DOS CONCEITOS DE BOURDIEU
}

\author{
TALITA CRISTINe RUgerI \\ Pedro Francisco Marchioro \\ Universidade Federal do Paraná (UFPR), Curitiba, Paraná, Brasil
}

\begin{abstract}
Resumo: Este artigo é resultado de uma reflexão sobre os usos da língua materna entre imigrantes alemães e de seu capital linguístico durante a nacionalização das escolas étnicas no período do Estado Novo. O artigo procura estabelecer entendimentos sobre a relação das escolas como instituições fundamentais das colônias imigrantes com as práticas culturais na Alemanha, e como a obrigatoriedade do uso do português dentro e fora dos espaços escolares gerou um processo de luta, disputas e resistência, encerrada na mobilização da língua enquanto recurso estratégico. Para análise do uso estratégico da língua na imigração alemã, lançamos mão do aparato conceitual de Pierre Bourdieu (1996), assim como de entrevistas semiestruturadas realizadas com quatro imigrantes e descendentes alemães, permitindo compreender como a linguagem é determinante da construção do mundo social e nas relações de poder.
\end{abstract}

Palavras-chave: Imigrantes Alemães. Escolas Étnicas. Nacionalização da Língua. Capital Linguístico.

\section{INTRODUÇÃO}

O período entre meados do século XIX e início do século XX no Brasil foi fortemente marcado por políticas de estímulos à imigração partindo, sobretudo, da Europa. A vinda de várias etnias europeias se inscreve no cerne de um projeto econômico, mas fortemente marcado por uma política racial, como o branqueamento da população brasileira'. Assim, a maior parte dos imigrantes europeus que se lançaram na empreitada migratória veio se estabelecer na região sul, sendo Paraná, Santa Catarina e Rio Grande do Sul, regiões essas pouco povoadas e com climas muito próximos aos encontrados na Europa.

Segundo Souza (2006), cerca de 100 mil imigrantes alemães, italianos, poloneses, japoneses e de outras nacionalidades chegaram ao Brasil entre 1829 e 1920, fixando-se no estado do Paraná: "Estima-se que, entre 1865 e 1899, dos 771.609 imigrantes que entraram no Brasil, 39.745 eram alemães, ao passo que no período 18901914, do total de 2.524 .504 imigrantes aqui chegados, 50.583 seriam alemães" (SOUZA, 2006, p. 41).

Os imigrantes alemães se concentravam em colônias nos três estados da região sul e, no Paraná, estavam presentes em maior medida nas cidades de Curitiba, Ponta 
Grossa, Palmeira, Rio Negro, Prudentópolis, Irati, Guarapuava, Cambé, Rolândia, entre outras. Estabelecendo-se nessas cidades, as colônias realizavam nas suas práticas toda a bagagem cultural trazida do seu país de origem, exteriorizando-a na arquitetura, religião, formação social, econômica e política. Segundo Teixeira (2008), suas ações e culturalidades:

\begin{abstract}
[...] se concretizaram em clubes, sociedades beneficentes, escolas, associações políticas e artístico-culturais onde recriaram-se traços de sociabilidades exercidas na Europa. Inadvertidamente, ou em decorrência do caráter homogeneizante dos processos de recriação cultural, ou ainda pela disseminação do ideário nacionalista, tais instituições passaram a ser reconhecidas como próprias dos imigrantes "alemães, italianos", "portugueses", "ucranianos", "poloneses", "suíços" e de tantos outros (TEIXEIRA, 2008, p. 77).
\end{abstract}

Dentre esses espaços de recriação dos traços de sociabilidade, destacam-se as escolas como espaços fundamentais de suporte para as demais atividades de exercício e atualização da cultura alemã. A preocupação com o ensino estava em sintonia com o estágio de desenvolvimento em que se encontrava o sistema educacional na Alemanha. O número elevado de escolas alemãs em comparação com as outras nacionalidades migratórias (considerando as proporções), superando em mais de três vezes o seu número, evidencia o peso diferencial que essa instituição tinha na cultura daqueles imigrantes alemães:

\begin{abstract}
Mesmo existindo essa controvérsia, o Brasil chegou a ter em tomo de 2.500 escolas étnicas em 1930. Dessas escolas, 1.579 eram de imigrantes alemães (LEHRERKALENDER, 1931), 396 de imigrantes italianos (TRENTO, 1989), 349 de imigrantes poloneses (WACHOWICZ, 1970) e 178 de imigrantes japoneses (VÁRIOS AUTORES, 1992) (KREUTZ, 2010, p. 2).
\end{abstract}

No que se refere ao conteúdo do projeto e do exercício escolar, as práticas pedagógicas orientavam-se pelos mesmos princípios da instituição na Alemanha, sendo trazido de lá o mesmo material didático.

Posta a centralidade da escola, por sua vez, para a transmissão dos conhecimentos e das disciplinas, o ensino da língua alemã era tido como um instrumento de conservação dos princípios da tradição, manutenção da cultura e formação da identidade em território de imigração. A língua, portanto, mais do que suporte cultural, abria-se como um elo entre o mundo de origem e esses sujeitos que foram obrigados a deixá-lo, e que deveriam reconstruir suas vidas em outro país sob o imperativo de não abandonar as suas "origens".

Avançada na primeira metade do século $\mathrm{XX}$, as colônias de imigrantes alemães ${ }^{2}$ seriam confrontadas pelos impulsos de implementação do Estado nação brasileiro. Assim, a instituição do Estado Novo (1937-1945), visando assegurar a formação de uma identidade nacional, tinha entre seus pilares a assimilação das comunidades estrangeiras 
à cultura nacional, concluindo aqui o arco de povoamento ou embranquecimento começado no fim do século XIX. ${ }^{3}$

Essa formação da identidade nacional se impunha às colônias imigrantes como negação da sua própria cultura, encontrava na uniformização da língua, o português brasileiro, o principal veículo, ferramenta e indicador, isto é: dizer que a assimilação das culturas diferentes se faria pelo estímulo ou imposição da língua nacional e, ao mesmo tempo, daria a medida e o grau de assimilação das culturas imigrantes à cultura nacional. A língua portuguesa, também em processo de sistematização e padronização (WACHOWICZ, 1984), passaria a ser obrigatória. Essa política alcança seu ápice no Decreto 406/1938, que institui o fechamento de escolas étnicas e intervenção nas demais escolas ligadas às colônias, iniciando aí um processo de nacionalização compulsória que, na prática, significava a proibição do uso da língua alemã nos espaços escolares e até mesmo domiciliares.

É nesse ponto que o presente artigo se concentra, sendo nosso objetivo analisar como a estrutura nacional brasileira, em pujante formação naquele período de guerras, manifestava-se numa lógica de coerção aos imigrantes alemães, e como estes, através do uso da língua alemã, respondiam a essa formação estrutural de nacionalização rigorosa e compulsória. Através de entrevistas com imigrantes e descendentes alemães, este artigo busca compreender como o uso da língua de origem vem a ser um capital linguístico, isto é, um recurso diferencial nas escolas e comunidades alemãs. Nos perguntamos ainda como a língua abriu um espaço de disputas étnicas e como ela oferecia instrumentos para resistência e agenciamento frente a essa realidade.

Para a discussão proposta, o texto se divide em: contextualização histórica dos processos migratórios, análise da importância da educação escolar dentro das comunidades alemãs e do efeito da nacionalização das escolas durante o Estado Novo. Nesse sentido, nos referenciamos em Kreutz (2010), Poutigant e Streiff-Fenartpo (1998), Britto (2012), Renk (2005) e Wachowicz (1984). Seguimos a compreensão do uso da língua à luz de Bourdieu (1996), dialogando e sustentando as entrevistas realizadas com quatro imigrantes e descendentes alemães. Concluímos que a proibição do uso da língua alemã entre imigrantes no Brasil, sobretudo com a intervenção escolar, gerou a desvalorização de uma competência linguística, alterando o mercado e a maneira como tal competência operava.

\section{A FORMAÇÃO DAS ESCOLAS ÉTNICAS}

As comunidades alemãs em Curitiba se dividiam entre católicos, protestantes, menonitas e luteranos, com escolas mantidas por paróquias e todas elas ministrando as suas aulas em alemão, ou português e alemão. A exemplo, podemos citar o Colégio Erasto Gaertner, localizado no bairro Boqueirão, o Colégio Bom Jesus e o Deutsche Schule, localizados no centro da cidade. Caso as aulas não ocorressem em espaços e salões paroquiais, seriam realizadas/improvisadas em clubes da comunidade.

O ensino da língua alemã tinha peso determinante sobre as demais disciplinas escolares, sendo suporte para perpetuação de todos os demais elementos culturais, de identidade e de vinculação ao território e à cultura de origem. Neste trabalho não adentramos nas especificidades e variações que a ampla e volumosa imigração alemã pressupõe, mas assumimos a tendência em considerar que, a despeito das variações 
regionais, de classe e religiosas, o peso da língua era um denominador comum/igualmente compartilhado. O exercício da religião e da fé, por exemplo, estavam em primeiro plano e dependiam inteiramente de um certo ensinamento e controle da língua. Desse modo, entre os alemães menonitas, por exemplo, a gestão da escola era delegada e distribuída à comunidade, com atenção direcionada à língua, que aparecia como disciplina fundamental para a manutenção da comunicação e como transmissão dessa e mesmo das outras matérias e disciplinas (MASKE, 2016).

Nesse sentido, mesmo com as diferenças religiosas, todas as matrizes tinham a preocupação em lecionar o alemão, em trazer materiais e preparar professores. $O$ ensino da língua e a sua articulação estreita com a religião enquanto sustentáculo dos laços da comunidade colocavam nas escolas e na educação dos imigrantes o papel do que Kreutz (2010) denominou escolas étnicas.

Como ilustração da dinâmica dessas escolas étnicas, no Arquivo Público do Paraná existem registros com solicitações para a vinda de professores da Alemanha para o Brasil como forma de proporcionar o ensino legítimo e consagrado da língua e da cultura alemã. A manutenção de um sentimento de pertencimento à nação pode ser percebida como um caráter de etnicidade (PUTIGNAT; STREIFF-FENARTPO, 1998), ou pertencimento a um grupo reforçado e legitimado pelo uso da língua dentro da comunidade, ainda que precisassem aprender o português.

Para estabelecer uma condição de pertencimento ao grupo étnico, é preciso levantar marcadores de pertença por aqueles que reivindicam uma origem comum (OLIVEIRA, 2006). Nesse sentido, não basta ter a mesma língua, viver no mesmo espaço, mas observar o modo como os significados e simbologias, exercidos e atualizados nas interações entre os sujeitos, operam em condições cognitivas e afetivas e passam a validar os comportamentos dos integrantes do grupo (PUTIGNAT; STREIFF-FENARTPO, 1998).

É importante relembrar que, de acordo com Seyferth (1981), o processo educacional ocorre na Alemanha desde a Idade Média com as escolas monásticas voltadas às práticas religiosas e ensinamentos do sagrado. No século XIX, com influências da Revolução Francesa, uma nova visão de educação é posta e evolui rapidamente para todo o território nacional alemão. Um exemplo dessa expansão é a força que assume o romantismo alemão, expresso em Os sofrimentos do jovem Werther de Goethe, publicado em 1850 e causando euforia (e uma onda de suicídios românticos) nas cidades alemãs da época. Esse é o período de ebulição cultural na Alemanha, do Aufklarung, correspondente à efervescência cultural da vizinha Revolução Francesa.

É ainda desse período o neo-humanismo ${ }^{4}$, muito forte na Alemanha, que influencia a pedagogia moderna no sentido de formação de indivíduos dotados de razão com uma formação social, humanitária e cultural, sendo o Estado a instituição determinante para implementar as Reformas Educacionais e desenvolver indivíduos que reconheçam o poder estatal. Essa proposta de uma escola elaborada e garantida pelo Estado tem um caráter político, filosófico e social, ${ }^{5}$ e prevê a elaboração de indivíduos autônomos, sistematizada no conceito de Bildung. 
RUGERI, T. C.; MARCHIORO, P. F.

Em oposição ao conceito de Kultur, que designou, a partir de então, o estado externo da cultura, suas instituições públicas, seu horizonte ideológico coletivo, a Bildung refere-se ao processo de autodesenvolvimento, de autoformação dos indivíduos no que diz respeito à sua educação. $O$ que este termo sublinhava era a importância incontornável da dimensão ativa da individualidade no processo de formação cultural (BRITTO, 2012, p. 222).

O conceito de Bildung ajuda a construir um modelo de ensino e cultura alemão que propõe a educação escolar como um bem público, ainda que uma parcela da população na Alemanha, principalmente das áreas rurais, tivesse acesso apenas ao ensino primário. Tal concepção vai sendo integrada na população alemã e, reconhecido seu êxito, copiado por países europeus (BRITTO, 2012). Os imigrantes alemães que aqui chegam, à diferença das demais imigrações (italiana, japonesa, por exemplo), tinham o conhecimento e a percepção desse projeto, do Bildung, e cabia à escola avançar no reforço de incorporação e inscrição de seus preceitos nas práticas e nos pensamentos dos imigrantes alemães.

Em comparação, no Brasil, até os anos 1940, as poucas escolas públicas que havia eram para a elite, principalmente nas áreas urbanas. Nesse período, a Constituição brasileira dava autonomia aos municípios para a criação e manutenção das escolas primárias, e as poucas escolas municipais eram mantidas precariamente pelas pequenas comunidades existentes.

As famílias alemãs, ao chegarem no Brasil e tendo na escola uma instituição fundamental para o desenvolvimento das crianças e, consequentemente, das comunidades, passam imediatamente a formar grupos escolares, ainda que não regulamentados e reconhecidos pelo Estado brasileiro. ${ }^{6}$

A maioria dessas escolas realizava a cobrança pela instrução e manutenção dentro das paróquias e comunidades, e obedecia ainda ao imperativo de organização e manutenção das práticas culturais. A escola é tratada como uma extensão da família, e o processo de autogestão das comunidades era realizado por essas famílias e figuras religiosas, uma vez que as colônias não eram compostas por um grande número de pessoas, variando de "300 indivíduos, com pico de 1.295 para a colônia Thomaz Coelho (atual município de Araucária, região metropolitana de Curitiba) e um mínimo de 98 para a colônia de D. Pedro em Curitiba" (OLIVEIRA, 2007, p. 4), o que facilitava a manutenção dessas comunidades.

\section{AS ESCOLAS ALEMÃS E A NACIONALIZAÇÃO COMPULSÓRIA}

Na virada do século XIX, o número expressivo de escolas étnicas, e em maior medida aquelas em que inexistia o português como língua de alfabetização, passa a ser alvo de preocupação do governo brasileiro em vias de avanço no processo de construção da identidade nacional e uniformização da língua. ${ }^{7}$ No entanto, é no Estado Novo que esses impulsos se definem. O Estado Novo compreende o período de 1937 até 1945, e, em parte devido ao contexto de guerra, que obrigava à intensificação nas políticas de defesa e vigilância e, em parte por uma tendência de conclusão da modernização do Estado a que os países do sul ainda não haviam alcançado, foi marcado por práticas autoritárias, em nosso caso, expressa na interdição de 
modalidades culturais variantes, decisivamente aquelas associadas às "nações inimigas", e, por fim, na proibição da língua enquanto meio de possibilidade das demais vertentes.

O presidente da época, Getúlio Vargas, era taxativo quanto à necessidade de construção de uma identidade nacional. Em seu livro As diretrizes da nova política do Brasil, de 1943, Vargas descreve a base de sua política nacional, reforçando que a unificação do Brasil só ocorreria através da educação e da obrigatoriedade do português. Neste livro, a questão geográfica e demográfica do Brasil ganha o primeiro plano, assim como a necessidade de políticas de intervenção nas colônias de imigrantes da região sul.

Em 1938, é editado o Decreto 406, que nacionaliza compulsoriamente todas as escolas do Brasil, ou seja, são proibidas as escolas étnicas, e todas as escolas deveriam ser nacionalizadas e o uso exclusivo da língua portuguesa passa a ser obrigatório, devendo ser fechadas as que não se adequarem: "Para bem esclarecer a ideia, devo dizer-vos que o Brasil, politicamente, é uma unidade. Todos falam a mesma língua, todos têm a mesma tradição histórica e todos seriam capazes de se sacrificar pela defesa de seu território" (VARGAS, 1943, p. 285). Além da obrigatoriedade da língua portuguesa, impunha-se outros elementos, como: canto dos hinos, exaltação de personagens considerados parte da formação cultural do Brasil e veneração da figura de Vargas. Intervindo no sistema escolar com reformas, divisão por classe e medidas compulsórias, era possível o controle e subordinação das comunidades estrangeiras ao poder do estado.

Nos Estados do Sul, São Paulo e Espírito Santo, a campanha da nacionalização fechou, no período de 1937 até 1941, 774 escolas particulares, que foram substituídas por 885 escolas públicas, abertas nos mesmos locais, assim como também concede auxílio especial a esses Estados para a construção de prédios escolares nas comunidades de imigrantes (AZEVEDO, 1996, p. 678-679 apud RENK, 2005, p. 9).

Em 1942 é promulgada a Reforma Capanema de regulamentação do ensino, sendo os principais pontos a divisão entre um ensino para as elites e um ensino profissionalizante para as classes pobres, no qual se encaixaria o ensino das colônias dos imigrantes europeus.

\section{A IMPOSIÇÃO DA LÍNGUA E A RESISTÊNCIA DOS SUJEITOS DE LINGUAGEM}

De fato, se não devemos esquecer a contribuição que a intenção política de unificação (também visível em outros campos, como o do direito) traz para a construção da linguagem que os linguistas aceitam como um dado natural, devemos ter cuidado para não atribuir-lhe toda a responsabilidade da generalização do uso da língua dominante, dimensão da unificação do mercado de bens simbólicos que acompanha a unificação da economia, e também da produção e circulação cultural. [...] visível em todos os domínios da 
RUGERI, T. C.; MARCHIORO, P. F.

prática (esporte, música, vestuário, habitat, etc.), o processo de unificação e a produção e circulação de bens econômicos e culturais leva à progressiva obsolescência do antigo modo de produção de hábitos e de seus produtos (BOURDIEU, 1991, p. 77).

A política de nacionalização por meio da educação gera efeitos nas colônias. As escolas que se rebelaram ao processo foram fechadas, e todas as demais eram rotineiramente visitadas por interventores que verificavam se estavam utilizando materiais proporcionados pelo governo brasileiro, como: cartilhas, fotografias, filmes de curta duração, uniformes, livros e atividades que demonstrassem amor à pátria, como desfiles, comemorações e manifestações. As professoras e professores foram fiscalizados pelo Departamento de Educação para verificar se lecionavam a escrita e a oralidade exclusivamente em português

As escolas alemãs foram as que mais apresentaram descontentamento com a obrigatoriedade do uso da língua portuguesa e da mudança curricular, tornando-se alvo das políticas de nacionalização, pois eram vistas pelo governo brasileiro como "perigo alemão" (RENK, 2005). Wachowicz (1984) afirma que muitos imigrantes pararam de mandar seus filhos às escolas nacionalizadas em razão da proibição do aprendizado pela língua que Ihes era original. Essa condição que foi posta aos imigrantes alemães imprime-se nos relatos realizados pelos imigrantes e descendentes.

\section{ENTREVISTAS E CAPITAL LINGUÍSTICO}

Nesta seção trataremos das entrevistas realizadas durante o ano de 2011 com quatro imigrantes e descendentes alemães. Duas entrevistas foram realizadas em um asilo de tradição menonita, localizado no bairro boqueirão da cidade de Curitiba, conhecido por ter a maioria dos seus moradores de descendência alemã. As outras entrevistas ocorreram com uma sobrinha e um amigo dos moradores do asilo. Foram questões semiestruturadas, realizadas durante 3 meses, e transcritas posteriormente. Devido à alta idade de alguns dos entrevistados, algumas das entrevistas ocorreram mais de 6 vezes, sendo 2 realizadas apenas com anotações devido à proibição da gravação oral, transparecendo a existência do medo vivido durante o período do Estado Novo. Muitas das conversas se estendiam por longos relatos cheios de sentimentos e lembranças.

A partir das entrevistas de Astrid, Lina, Herman e Franz, ${ }^{8}$ foi possível vincular a teoria de capital linguístico elaborado pelo sociólogo Pierre Bourdieu, permitindo compreender como ocorreu a instrumentalização do uso da nova língua, o português, em relação à língua materna, o alemão, no conflito com o Bildung e a nacionalização durante o Estado Novo, e a escola como espaço de formação social foi determinante nos processos de instrumentalização da linguagem.

A seguir, apresentaremos um primeiro relato para então abordar os conceitos de Bourdieu (1991) na forma como o autor propunha: um encadeamento entre teoria e realidade teorizada que, em última instância, coloca a teoria como subordinada à realidade analisada. $\mathrm{O}$ relato de Astrid nos dará um primeiro impulso para tanto. $\mathrm{A}$ análise da entrevista e a definição dos conceitos e categorias serão demonstradas na 
seção a seguir e in loco, isto é, no processo mesmo de operacionalização dos fenômenos e fatos a serem compreendidos.

ASTRID

Uma das entrevistadas, ${ }^{9}$ chamada Astrid, nasceu na Sibéria em 1929, mas morou por um curto período na Alemanha e seguiu com a família para o Brasil com aproximadamente 6 anos de idade. Juntos, desembarcaram em Santa Catarina e se estabeleceram em uma colônia até 1940, onde ela frequentou uma escola paroquial em que o idioma exclusivo era o alemão. Segundo Astrid, o alemão era a língua natural, a qual aprendera e na qual evoluía conforme ganhava idade, porém, na escola, encontrava variações no modo de empregá-lo tanto na fala quanto na escrita. Ela relata como os alunos se destacavam à medida que conseguiam executar a letra gótica, e como isso era motivo de orgulho para a família, sinal de aptidão para os domínios escolares e ofícios que exigiam a habilidade da escrita.

Em 1940, Astrid e a família se mudam para Curitiba e vão morar no bairro Boqueirão. Neste bairro encontram escolas já iniciadas no processo de nacionalização, em que o português se fazia língua obrigatória. A mudança foi traumática. Astrid conta que chegou a desistir dos estudos por não conseguir aprender o português e por não sentir necessidade em compreender a língua para sobreviver ao cotidiano fora da escola. Somente na adolescência os estudos foram retomados, período em que passou a ir ao centro da cidade comercializar as mercadorias e insumos que a família produzia.

Temos na fala de Astrid um primeiro ponto sobre a mudança da Alemanha para um Brasil cujo clima e geografia se assemelhava à Alemanha que Astrid conhecera em sua curta biografia, mas que ressurgiu em longo termo nas experiências revividas e rememoradas nas relações familiares e comunitárias. Nesse primeiro período, o Brasil não representava muito mais do que uma Alemanha distante e sutilmente variada, de modo que, superada a viagem cansativa, a vida na Alemanha não sofreu mais do que uma leve interrupção, um solavanco, transpondo-se para Santa Catarina, região em que se encontrou com outros alemães, que falavam a mesma língua e a valorizavam da mesma maneira. Assim, o alemão era a língua que usavam segundo os mesmos esquemas para definir o mundo e seus entes bons ou ruins e, já utilizando a nomenclatura de Bourdieu (2010), uma língua que oferecia um instrumental de percepção e apreciação do mundo e das relações que o mundo comporta.

Em um segundo ponto, Astrid revisita uma mudança cujo percurso geográfico é muito mais curto, porém, o deslocamento psíquico e subjetivo é muito superior. A mudança de Santa Catarina para Boqueirão, em Curitiba, significa o encontro com a terra imponente e desconhecida, com a condição estrangeira. Da perspectiva da língua, e em seu sentido amplo (comunicação, cultura, ética), a chegada em Curitiba significa a interrupção do ser naturalmente alemão, do questionamento do Bildung, da racionalização/objetivação da cultura alemã que, por exemplo, oferecia uma apreciação estética de sua língua (como narrou a informante sobre as formas góticas de desenhá-la, de entoá-la). Portanto, a mudança de Santa Catarina para Curitiba ganha o sentido de uma confusão ontológica em que a comunicação através da língua bela e elegante - a 
única na qual é possível filosofar, segundo Heidegger (1993) - dá lugar a uma língua "feia", "bastarda", imposta pela força policial.

Astrid repisa ainda esse outro ponto comum aos demais relatos: durante aquele período, no Boqueirão, assim como em outros bairros de Curitiba, existiam postos de fiscalização em que os habitantes deveriam se apresentar e comprovar (mediante a interpelação policial) que eram de fato (jus solis e jus sanguinis) ${ }^{10}$ brasileiros. A língua, mais uma vez, era ponto decisivo: aqueles que não conseguissem falar o português, ou que apresentassem sotaque, eram presos em celas no centro da cidade. Portanto, o português se associava objetivamente, naquela realidade, ao trato policial, à repressão física e, poderíamos afirmar, uma vez que se associa à polícia, à ordem; posiciona-se o alemão como antítese, logo, como desviante, interditado, e mesmo criminoso.

Finalmente, a proibição do alemão, compreendida na mudança de cidade e de escola por Astrid, significa uma fratura de identidade/realidade: se a língua é o vetor e portador do símbolo e do sentido de si (do sujeito da língua) e do mundo, uma vez que ela é interrompida, interditada, colocada no universo do "proibido", o aprendizado de uma nova língua, do português, não significa somente um outro conjunto de signos e de referências a ser aprendido e utilizado, mas a restituição e revestimento de um (novo) sentido ao mundo (desprovido de sentido); do mundo este que se revela no presente, ${ }^{11}$ mas também daquele que ficou no passado e do que se projeta no futuro. É dizer que a experiência vivida no passado, na Alemanha, diretamente por Astrid ou por seus familiares, deverá ser reeditada à luz da língua portuguesa, o que, como bem demonstrou Volochinov (2018), deve acarretar um ajustamento não só do símbolo, mas do sentido e mesmo da experiência. Ou, como afirma Bourdieu (2010), não se pode dizer qualquer coisa em qualquer língua:

\begin{abstract}
O paradoxo da comunicação é que ela supõe um meio comum mas que não consegue - vemos isso bem no caso limite onde se trata de transmitir, como é frequente na poesia, as emoções - se não suscitando e ressuscitando experiências singulares, quer dizer, socialmente marcadas (BOURDIEU, 2001, p. 62).
\end{abstract}

Ainda, tomando a língua como um capital no sentido de Bourdieu (1996), isto é, de recurso para intervenção ou agenciamento dos sentidos do mundo, temos de pensar como a cultura, isto é, não só o uso da linguagem, mas a relação com sua forma falada, escrita, lida, escutada, anteriormente incorporada e revivida por Astrid ou por sua família, servirá de suporte estratégico para a vida na (nova) realidade.

E de fato, num primeiro momento, vemos no relato de Astrid que a experiência com a língua falada e escrita (podemos chamar de relação com a língua), assim como a ameaça de abandono e substituição pelo português, leva-a a uma disposição de resistência e repúdio, de reprovação. Aqui vale a exposição do esquema conceitual bourdieusiano para abordarmos esse tipo de resposta imediata expressa por Astrid, de rejeição, e os possíveis sentimentos que restam assentes nos movimentos subsequentes à aceitação da nova ordem linguística.

UMA RÁPIDA DEFINIÇÃO: CAPITAL LINGUÍSTICO E MERCADO DE INTERCÂMBIO DOS CAPITAIS E EMPREGO DAS COMPETÊNCIAS 
Compreendendo a língua como uma competência exercida dentro de um mercado linguístico, podemos repensar a experiência de Astrid com a língua alemã (suas valorizações, as nuances percebidas nas grafias, o aparato sensível cognitivo apreendido e acionado em tais avaliações, o gosto pela leitura) em termos de investimento para a sua boa apropriação, isto é, do aprendizado do alemão não simplesmente como código comunicativo, funcional, mas como recurso simbólico sujeito à classificação no mercado linguístico e, portanto, capaz de auferir lucros ou prejuízos aos sujeitos portadores. Assim como se referiu às diferenças gráficas que reconhecia e que classificavam o "melhor" ou o "bom" alemão perante a família e a comunidade, também a expressão falada de algumas palavras é apreciada na comunidade/mercado linguístico, e sustentam classificar e posicionar o sujeito da fala/escrita.

Pois bem, uma vez que todo esse arsenal apreendido a um custo considerável (um investimento pessoal e familiar na aquisição dos capitais escolares e culturais que estão por trás do domínio e expressão de uma variante linguística) é questionado, ou mesmo proibido, toda a competência investida na língua se vê fracassada, suspensa, falida. A proibição do alemão e, consequentemente, a obrigação do português, foi colocada como a crise ou mesmo erosão completa de todo um mercado linguístico (análoga às crises financeiras que colapsam as relações produtivas e comerciais e que levam os sujeitos à depressão ou suicídio). A analogia tem seus limites: nem todas as competências são perdidas, ou poderíamos dizer que a competência em si permanece, sendo perdido o seu conteúdo (como os grandes players e comerciantes do mercado financeiro que perdem toda a sua fortuna, mas não o seu know how, isto é, não a sua habilidade e vantagem diferencial para ler o novo mercado e reconstruir uma nova fortuna a partir de novas relações). Do mesmo modo, os esquemas de apreensão e mobilização dos signos permanecem em posse do indivíduo interrompido (a despeito das mudanças significativas, traumáticas, que devem ser ponderadas). Não por acaso, esses descendentes de imigrantes, outrora violados em sua integridade física-subjetiva, lograram ocupar posições de destaque e de prestígio nos ofícios que exigem competência cultural e linguística, como veremos nos relatos a seguir.

Por fim, um dos efeitos sentidos de quem perdeu algo que antes tinha, ou que teve desvalorizado algo que antes era valorizado - sobretudo nos movimentos imediatamente posteriores a essa queda -, é buscar retornar à sua posição anterior simplesmente reprovando o que essa posição se tornou, sendo comum, por exemplo, o sentimento de ressentimento (em frases do tipo "antes é que se falava um alemão melhor", "a letra era desenhada com a pena... não era esse rabisco aí"), - ou o encolhimento amargurado em si mesmo, a introspecção individual, o mutismo. Ou, ainda, a afinidade a espaços de reclamação conjunta, isto é, em associação aos demais sujeitos que tiveram desvalorizados seus capitais. O capital linguístico atende a isso: sua valorização eleva a autoestima de seu portador e de sua cultura; sua desvalorização conduz a ações de respostas de resistência, repúdio, raiva, tristeza ou angústia.

Mas há mais. O aprendizado complexo do alemão, a valorização da língua, o gosto pela grafia e pela leitura, a apreciação na ou através da língua materna, tudo isso age de forma diferencial (no sentido que rende outro resultado) no novo mundo, visto a partir da necessidade de falar/instrumentalizar um novo idioma. Exemplo: aquele que 
aprendeu uma nova língua adquiriu não só novos signos de expressão, mas competências para aquisição de novos signos, uma abertura para o que se apresenta como interessante, como apto a ser investido.

LINA

Outra entrevistada, ${ }^{12}$ Lina, relatou que o seu pai chegou ao Brasil na década de 1930 e sempre comentava os incidentes de repressão pelos quais passou nos postos fiscais. Lina estudou o primário no Colégio Erasto Gaertner, onde aprendia apenas em alemão. Posteriormente, uma vez que o Colégio Erasto Gaetner era particular, Lina foi estudar em uma escola pública devido a dificuldades financeiras em que a família se encontrava. Seu pai, Johan, se recusava a falar o português tanto dentro como fora de casa. $E$, de fato, Lina relatou que ela e os irmãos eram repreendidos, ou que seus pais fingiam não compreender o que era dito. Porém, a prática diária em casa e o período escolar falando apenas em alemão proporcionou a Lina se tornar professora da língua alemã, o que ela considerada algo de prestígio.

Souza (2006), pesquisador da imigração alemã, afirma que muitos dos imigrantes alemães entendiam o aprendizado do português como um abandono e uma traição à cultura alemã, que, quando realizado, era experienciado como uma vergonha ou uma covardia, além do distanciamento à grandeza do Bildung.

A repressão relatada pelo pai de Lina e a estratégia de fingir não compreender ou negar aos filhos o uso da língua portuguesa alude tanto a uma relação individual e intersubjetiva (familiar) quanto a uma dimensão social-política que inevitavelmente é reportada a um contexto mais amplo. Nesse sentido, a proibição do uso da língua alemã, mesmo em caráter doméstico e cotidiano, é parte dos mecanismos de dominação e violência que definem o Estado ${ }^{13}$ e sua vigilância em relação à identidade e à língua. $\mathrm{O}$ fingimento também se torna uma estratégia, um recurso ou capital a ser utilizado nesse contexto de proibição, porém, que se imprime nas disposições práticas, isto é, no habitus, e é transmitido nas experiências posteriores daquele que viveu o contexto em que foi necessário o seu fingimento ou mesmo o dos seus descendentes. É uma dimensão estratégica da língua, um capital, um recurso que lhe é posto: saber o que está sendo dito e saber que não se pode demonstrar que se sabe, um saber de segundo ou terceiro grau. Típico de consciências clivadas, o trauma e a violência sofrida pelo pai são transmitidos aos filhos, um habitus coletivo/familiar, a transmissão da experiência que incide sobre os herdeiros e se imprime em suas práticas.

O sentimento de amargura é transmitido aos filhos, e fortalece a identidade alemã a partir da linguagem dentro da família, ou seja, o movimento de transmissão de um capital linguístico como parte do capital cultural. Isso é perceptível na profissão de Lina, pois ao manter o uso da língua alemã nas relações domésticas, e com o ensino primário em uma escola tipicamente alemã, ela usa a força do capital cultural herdado, encontrando um mercado para esse capital incorporado como uma condição de prestígio.

A relação distanciada (que provavelmente privilegiou um senso estético de apreciação ou saudosismo, nostalgia) com o alemão "leva" Lina de alguma forma a ser uma profissional da língua reprimida, da cultura cerceada. Profissional aqui no sentido de dar a vida a um ofício que constitui suas relações sociais; de comprometer-se por 
completo, anexar sua identidade (social e subjetiva) a isso, ao alemão, em um contexto em que ele retorna ao plano valorizado, de classificação em potência, já que gera sentimento de prestígio, como ela afirma.

\section{HERMAN E FRANZ}

O imigrante Herman nasceu em 7 de junho de 1930 e nos informou ${ }^{14}$ que até os seus 7 anos de idade falava apenas alemão dentro de casa, e aprendeu português quando estudou o primário no Colégio Santa Maria. Herman se lembra da perseguição que ocorria com os alemães durante a Segunda Guerra, e como tentava disfarçar o sotaque com medo de retaliações, mas que dentro de casa falavam alemão em voz baixa para que os vizinhos brasileiros não escutassem. O entrevistado também nos relatou como a família gostaria que ele tivesse estudado no Colégio Bom Jesus, na época chamado de Escola Católica Elementar Alemã de Curitiba, a primeira escola católica alemã da cidade, devido ao prestígio que o grupo escolar tinha dentro da comunidade. ${ }^{15}$

Nesse relato é visível novamente uma condição estratégica do uso da linguagem ao disfarçar o sotaque quando se falava em português. Tal situação apresenta o uso de uma competência linguística como forma de resistência, ou seja, uma resposta estratégica a uma situação complexa e turbulenta.

O entrevistado Franz nasceu em Joinville/Santa Catarina, ${ }^{16}$ em $1^{\circ}$ de abril de 1921, descendente de alemães recém-chegados ao Brasil. Franz estudou na escola pública em Rio Negro, onde aprendeu português com dificuldade, pois os pais não sabiam falar a língua portuguesa. Nos anos 1930 veio com a família morar em Curitiba e estudou no antigo Deutsche Schule, escola situada onde atualmente é a praça 19 de Dezembro no centro da cidade. A escola foi depredada em 1917 por conflitos entre moradores brasileiros devido à Primeira Guerra Mundial, que consideravam a escola alemã uma ameaça ao país. ${ }^{17}$ Posteriormente, a escola foi mantida até 1940 como Colégio Progresso, após esse ano foi destruída para ampliação da avenida.

Herman relatou a lembrança do dia da proibição do uso do alemão como língua oficial da escola e da tristeza dos professores, funcionários e alunos. Afirmou também que o ato de falar alemão dentro da comunidade era motivo de alegria e orgulho. Retomamos aqui a relação do sentimento embutido no uso da língua de origem, uma parte da construção do Bildung. A etnicidade construída nessa perspectiva opera nas relações cognitivas e afetivas, mas também na unificação da língua como um bem simbólico nas relações práticas, do sentir e relatar o orgulho que atua na relação pertencimento/competência.

As escolas relatadas por Herman e Franz já tinham legitimidade dentro da comunidade alemã e haviam conquistado certo prestígio, gerando distinção entre os imigrantes. Aqueles que conseguiram manter seus filhos por mais tempo nessas escolas até o Decreto 406 garantia maior prestígio dentro das colônias, expandindo os sentimentos de tristeza no processo de fechamento das escolas.

\section{CONSIDERAÇÕES FINAIS}


Destacamos a relação dos imigrantes alemães com a língua materna, como uma forma de reviver as práticas sociais e culturais realizadas na Alemanha, uma vez que o Brasil está em processo de formação enquanto estado-nação no período analisado. A sociabilidade dentro dessas comunidades é marcada, portanto, pelo uso da língua alemã, tanto nas relações familiares quanto escolares, uma vez que a escola é tratada como extensão da família. Nesse caso, podemos dizer uma relação direta entre família, escola e igreja, e essa tríade estrutura elementos fundamentais para a formação cultural alemã, do Bildung.

A partir das políticas de nacionalização, e especificamente com o Decreto 406 de 1938, o choque com a nova imposição política é posto, principalmente pela obrigação da língua portuguesa e proibição do uso de línguas estrangeiras.

O descontentamento apresentado pelos imigrantes alemães com a nacionalização das escolas, interferência do uso do alemão em locais públicos e até mesmo no interior dos seus lares contribui para elaboração de estratégias de sobrevivência do uso da língua materna, como podemos observar nos relatos, o disfarce do sotaque, o silenciamento em locais públicos, ou nas relações pessoais, são maneiras de reviver a língua alemã se opondo a nova condição.

Tais estratégias possibilitam a capitalização das práticas culturais alemãs através da linguagem. O resgate da memória das experiências dos pais e demais familiares, no interior do mercado linguístico cultural atual, é um exemplo de tal capitalização, como retratado no ato de lecionar alemão descrito por Lina. À luz de Bourdieu (1991), podemos afirmar que a proibição do uso da língua alemã entre imigrantes no Brasil, sobretudo com a intervenção escolar, gerou, portanto, a desvalorização de uma competência linguística. Ao alterar o mercado no qual tal competência opera, não se modifica apenas o ato de falar a língua de origem, mas, também, na interferência da identidade, da etnicidade, criando sentimentos de ressentimento, amargura, orgulho ferido e saudosismo.

Nesse sentido, a língua se torna um instrumento de diferenciação e aproximação, a língua não está na função apenas de comunicação, mas na produção de um mundo social, onde a linguagem é estabelecida por relações de poder. Essas relações são postas por Pierre Bourdieu ao afirmar que a língua não é uma condição em si mesma, ou seja, não garante sua existência por si, mas sim no sentido social que uma coletividade lhe atribui, um reconhecimento que lhe é conferido (BOURDIEU, 2010).

Artigo recebido em: 01/04/2021

Aprovado para publicação em: 28/05/2021

THE USES OF LINGUISTIC COMPETENCE AMONG GERMAN IMMIGRANTS DURING THE ESTADO NOVO IN CURITIBA: A MIGRATORY ANALYSIS IN THE LIGHT OF BOURDIEU'S CONCEPTS

ABSTRACT: This article is the result of a reflection on the uses of the mother tongue among German immigrants and their linguistic capital during the nationalization of ethnic schools during the Estado Novo period. The article seeks to establish understandings about the relationship of

Inter-Ação, Goiânia, v.46, n.2, p. 523-539, maio/ago. 2021. Disponível em: <http://dx.doi.org/10.5216/ia.v46i2.68480>. 
schools as fundamental institutions of immigrant colonies with cultural practices in Germany, and how the mandatory use of Portuguese inside and outside school spaces generated a process of struggle, disputes, and resistance ended in mobilization language as strategic resources. To analyze the strategic use of language in German immigration, we used the conceptual apparatus of Pierre Bourdieu (1996), as well as semi-structured interviews carried out with four immigrants and German descendants, allowing us to understand how language is determinant in the construction of the social world and in Power relations.

KEYWORDS: German Immigrants. Ethnic Schools. Nationalization of the Language. Linguistic Capital.

LOS USOS DE LA COMPETENCIA LINGUÍSTICA ENTRE INMIGRANTES ALEMANES DURANTE EL ESTADO NOVO EN CURITIBA: UN ANÁLISIS MIGRATORIO A LA LUZ DE LOS CONCEPTOS DE BOURDIEU

RESUMEN: Este artículo es el resultado de una reflexión sobre los usos de la lengua materna entre los inmigrantes alemanes y su capital lingüístico durante la nacionalización de las escuelas étnicas durante el período del Estado Novo. El artículo busca establecer entendimientos sobre la relación de las escuelas como instituciones fundamentales de las colonias de inmigrantes con las prácticas culturales en Alemania, y cómo el uso obligatorio del portugués dentro y fuera de los espacios escolares generó un proceso de lucha, disputas y resistencias que terminó en el lenguaje de la movilización. Como recursos estratégicos. Para analizar el uso estratégico de la lengua en la inmigración alemana, se utilizó el aparato conceptual de Pierre Bourdieu (1996), así como entrevistas semiestructuradas realizadas a cuatro inmigrantes y descendientes de alemanes, lo que nos permitió comprender cómo la lengua es determinante en la construcción del mundo social y en las relaciones de poder.

PALABRAS CLAVE: Inmigrantes Alemanes. Escuelas Étnicas. Nacionalización de la Lengua. Capital Linguístico.

\section{NOTAS}

1 - Ver: SEYFERTH, G. Construindo a nação: hierarquias raciais e o papel do racismo na política de imigração e colonização. In: (AUTORES). Raça, ciência e sociedade. Rio De Janeiro: Fiocruz, 1996. p. 41-59.

2 - Conta-se, nesse período, duas ou três gerações no Brasil.

3 - Isso, sobretudo, em razão da abolição da escravatura e da entrada no regime da produção industrial e do assalariamento (NOVAES, 1986).

4 - O neo-humanismo alemão é um novo movimento que surge do humanismo nos séculos XV e $X V I$, que no século XIX tem como figura central Wilhelm Von Humboldt, que inicia uma nova era da pedagogia moderna a partir de visões antropocêntricas que busca formar o indivíduo em um ser completo (educação, formação e cultura).

5 - A exemplo da criação da Universidade de Berlim em 1810.

Inter-Ação, Goiânia, v.46, h.2, p. 523-539, maio/ago. 2021. Disponível em: <http://dx.doi.org/10.5216/ia.v46i2.68480>. 
RUGERI, T. C.; MARCHIORO, P. F.

6 - As associações culturais, mais a comunidade, as igrejas e escolas, asseguravam uma relação intensa com a Alemanha. $\mathrm{Na}$ escola, as atividades curriculares e extracurriculares asseguravam a manutenção das relações culturais com a pátria de origem, como o estudo da língua materna e o currículo com hinos, música, história e geografia da Alemanha (RENK, 2005, p. 2).

7 - Sobre as escolas étnicas serem foco de políticas de nacionalização desde a virada do século, ver: WACHOWICZ, L. A. Relação Professor-Estado no Paraná Tradicional. São Paulo: Cortez, 1984.

8 - Os entrevistados são nomeados com nomes fictícios e aleatórios.

9 - Entrevista realizada de março a junho de 2011.

10 - É sabido que no Brasil e demais países do continente americano a lei pauta-se sobre o território do nascimento (jus solis) para atribuição ou não de cidadania. Porém, esse caso de estado quase de exceção, em que era dado ao policial ou guarda a autoridade para reconhecer se alguém era ou não brasileiro, vemos como a efetividade - alcance e força - da lei fracassa. Aqui, como vemos nos relatos, era sobre o sotaque e a modulação das palavras ditas (e segundo o ouvido policial) que se decidia quem era ou não cidadão, quem ia ou não para a cadeia. Portanto, confundindo ou ignorando deliberadamente a normatização de descendência ou nascimento como condição de pleno cidadão brasileiro.

11 - É com intenção de insinuar uma associação ao conceito de Dasein, de Heidegger, e respeitando o ambiente da pesquisa, que empregamos a sua frase "mundo tal como se revela no presente", e que se amalgama com a linguagem e que se fratura, entra em crise, produz angústia quando é desassociado da língua enquanto seu suporte fundamental. A despeito do hermetismo de que é acusado o conceito, abrimos essa nota com o intuito (por certo ousado) de demonstrá-lo em ocorrência em tais práticas.

12 - Entrevista realizada em março de 2011.

13 - No sentido de Weber (1982), a proibição da língua entraria como parte elementar da dominação tradicional e racional-legal, ou seja, pela interferência na tradição cultural incorporada principalmente pela língua, e pela lei com a proibição do uso do alemão e intervenção curricular nas escolas.

14 - Entrevista realizada em 29 de abril de 2011.

15 - A escola também ensinava português devido à necessidade de comunicação no Brasil, mas todo o currículo escolar era baseado no sistema de ensino alemão.

16 - Entrevista realizada de março a abril de 2011.

17 - Imagens e textos publicados pelo jornalista Cid Destefan na Gazeta do Povo, Coluna Nostalgia, em 20 de agosto de 1989.

\section{REFERÊNCIAS}

BOURDIEU, Pierre. O poder simbólico. 13 edição. Rio de Janeiro: Bertrand Brasil, 2010.

BOURDIEU, P. Langage et pouvoir symbolique. Paris: éditions Foyard, 1991.

BOURDIEU,P. A economia das trocas lingüísticas. São Paulo: Editora da Universidade de São Paulo, 1996.

BRASIL, Constituição (1934). As Constituições dos estados e da República. Rio de Janeiro: Imprensa Nacional, 1937896 p. 
BRITTO, F. L. Identidade cultural e formação individual: a Alemanha do século XIX e a fundação da pedagogia moderna. Educação \& Sociedade (Impresso), Campinas, v. 33, n. 118, p. 217-233, 2012.

HEIDEGGER, M. El ser y el tiempo. Tradución de José Gaos. Mexico: Fondo de Cultura Económica, 1993.

KREUTZ, L. Escolas étnicas no Brasil e a formação do estado nacional: a nacionalização compulsória das escolas dos imigrantes (1937-1945). Poiésis, Tubarão-Santa Catarina, v. 3, n. 5, p. 71-84, 2010.

MASKE, W. A experiência escolar dos alemães menonitas no Brasil (1930-1970). In: RENK, V. E. (org.). Imigração, educação e escolar étnicas no Paraná. Curitiba: PUCPRess, p. 165-192

NOVAIS, F. Estrutura e dinâmica do antigo sistema colonial. São Paulo: Editora Brasiliense, 1986.

OLIVEIRA, M. de. Imigração e diferença em um estado do sul do Brasil: o caso do Paraná. Nuevo Mundo-Mundos Nuevos, v. 7, $2007 . \quad$ DOI: https://doi.org/10.4000/nuevomundo.5287. Disponível em: http://journals.openedition.org/nuevomundo/5287. Acesso em: 10 ago. 2021.

OLIVEIRA, R. C. de. Caminhos da identidade: Ensaio sobre etnicidade e multiculturalismo. São Paulo: Editora Unesp; Brasília: Paralelo, 2006

PARANÁ. Decreto n. 1.874 de 29 jul. de 1932. Regimento Interno das Escolas. Curitiba: Irmãos Guimarães \& CIA, 1932.

PARANÁ. Relatório de Governo, Realizações do Governo de Manoel Ribas (19371942). Curitiba: DEAP.

PARANÁ. Relatório de Governo, Realizações do Governo de Manoel Ribas (19321939). Curitiba: DEAP.

PARANÁ. Inspector Geral de Ensino. Paraná: Secretaria da educação, 1920.

POUTIGANT, P.; STREIFF-FENART, J. As teorias da Etnicidade. São Paulo: Fundação Editora da UNESP, 1998.

SEYFERTH, G. Nacionalismo e identidade étnica: a ideologia germanista e o pertencimento étnico Teuto-Brasileiro numa comunidade no Vale do Itajaí. Florianópolis: F. C. C., 1981. 
RUGERI, T. C.; MARCHIORO, P. F.

SOUZA, R. M. S. Deutsche Schule, a Escola Alemã de Curitiba: um olhar histórico (18841917). 2006. Tese (Doutorado em Educação) - Setor de Educação, Universidade Federal do Paraná, Curitiba, 2006.

RENK, V. E. Educação de Imigrantes alemães em Curitiba. Revista Diálogo Educacional (PUCPR), Curitiba, v. 5, n. 1, p. 101-112, 2005.

TEIXEIRA, V. M. Histórias de Curitiba. Fundação Cultural de Curitiba. Curitiba: FCC, 2008.

VARGAS, Getúlio. As Diretrizes da Nova Política do Brasil. Empresa Gráfica da "Revista dos Tribunais" Ltda. Rio de Janeiro, 1943.

VARGAS, G. A nova política do Brasil I: da aliança liberal as realizações do primeiro ano de governo. 1930/1931. Editora livraria Olympio. Rio de janeiro, 1930.

VOLÓCHINOV, V. Marxismo e filosofia da linguagem: problemas fundamentais do método sociológico na ciência da linguagem. São Paulo: Editora 34, 2018.

WACHOWICZ, L. A. Relação Professor-Estado no Paraná Tradicional. São Paulo: Cortez, 1984.

WEBER, M. Ensaios de sociologia. $5^{\circ}$ ed. Rio de Janeiro: Guanabara Koogan, 1982. 530 p.

Talita Cristine Rugeri: Doutoranda em sociologia pelo Programa de Pós-graduação em Sociologia pela Universidade Federal do Paraná. Mestre (2014) em educação e graduada (2012) em licenciatura em Sociologia pela Pontifícia Universidade Católica do Paraná. Atualmente compõe a comissão executiva da Revista Sociologias Plurais (UFPR) e é integrante do grupo de pesquisa em Educação e Bioética (PUCPR). Foi professora visitante na Pontifícia Universidade Católica do Paraná de 2016 a 2019 e do programa PARFOR pela Universidade Federal do Paraná em 2013.

Orcid: https://orcid.org/0000-0002-8355-1160

E-mail: talitarugeri@gmail.com

Pedro Francisco Marchioro: Possui graduação em Ciências Sociais pela Universidade Federal de Pelotas e Mestrado em Sociologia também pela UFPel. Doutorando em Sociologia pela Universidade Federal do Paraná (UFPR). Foi doutorando em sociologia pela Université Sorbonne Nouvelle - Paris 3, e pesquisador pelo Institut des hautes études de l'Amérique latine (IHEAL), em Paris. Entre as suas pesquisas destacam-se as áreas da Sociologia do Trabalho, das Imigrações e ldentidades. É membro do Núcleo de Estudos do Polo Naval e do Grupo de Pesquisas sobre os Haitianos no Paraná.

Orcid: https://orcid.org/0000-0002-5003-4538

E-mail: pedro-marchioro@live.com

Este periódico utiliza a licença Creative Commons Attribution 3.0, para periódicos de acesso aberto (Open Archives Initiative - OAI).

Inter-Ação, Goiânia, v.46, n.2, p. 523-539, maio/ago. 2021. Disponível em: <http://dx.doi.org/10.5216/ia.v46i2.68480>. 